UDC: 615.457 .015

doi:10.5937/hpimj1801581V

\title{
Pharmacodynamic Approach for Proving Equivalence of Two Ophtalmic Solutions Containing Brimonidine Tartarate $0.2 \%$ in Healthy Volunteers
}

\author{
Ruska Valcheva Hristova ${ }^{1}$, Irenna Stojanova Demircheva ${ }^{1}$, \\ Andrey Dimitrov Petrov ${ }^{2}$, Emil M. Gatchev², Ursula Thyroff-Friesinger ${ }^{3}$, \\ Wolfram Hagen Richter ${ }^{4}$, Rossen Krumov Koytchev ${ }^{4}$ \\ ${ }^{1}$ Medical University of Sofia, Clinic of Ophthalmology, University Hospital "Tsaritsa \\ Joanna-ISUL", Bulgaria \\ ${ }^{2}$ Medical University of Sofia, Department of Clinical Pharmacology and Therapeutics, \\ University Hospital "Tsaritsa Joanna-ISUL", Bulgaria \\ ${ }^{3}$ Hexal AG, Holzkirchen, Germany \\ ${ }^{4}$ Cooperative Clinical Drug Research and Development AG, Hoppegarten, Germany
}

\section{SUMMARY}

Introduction: Bromonidine tartarate ophthalmic solution (CAS registry-number: 7035946-5) is a relatively selective alpha-2 adrenergic agonist, indicated for the lowering of intraocular pressure in patients with open-angle glaucoma or ocular hypertension.

Aim: The purpose of the present phase- 1 clinical trial was to assess the pharmacodynamic equivalence of two ophtalmic solutions containing brimonidine tartarate $0,2 \%$ in healthy volunteers.

Methods: The study was performed as a single center, randomized, single-dose, observer-blinded, single period trial in 36 healthy volunteers. Each volunteer received successively and in a random way a single dose of 1 drop of the test or the reference product in the conjunctival sac of the right and left eye, respectively. Measurement of intraocular pressure (IOP) of both eyes was performed at screening examination, pre-dose and 2 hours post dosing and at final examination by means of a Goldmann applanation tonometer. The primary target parameter for proving pharmacodynamic equivalence was defined as the absolute decrease in IOP 2 hours post dose. The $95 \%$ confidence interval was calculated for the difference (test-reference) of the primary target parameter and compared with the pre-defined equivalence rangeof \pm 1.5 $\mathrm{mmHg}$.

Results: A decrease in the IOP of $4.60 \pm 1.26 \mathrm{mmHg}$ and $4.40 \pm 0.89 \mathrm{mmHg}$ was observed after administration of the test and reference formulation, respectively. The mean difference was $+0.197 \mathrm{mmHg}$ with a $95 \%$ confidence interval between -0.275 and 0.670 $\mathrm{mmHg}$ and thus entirely within the pre-defined equivalence range. Both products showed a very good local safety profile and similar tolerability.

Conclusion: Brimonidine Tartrate Ophthalmic Solution $0.2 \%$ was pharmacodynamical- 
ly equivalent to the reference preparation $\left(\right.$ Alphagan $\left.^{\circledast}\right)$ with respect both to efficacy and safety.

Keywords: pharmacodynamic equivalence, brimonidine, ophthalmic solution

\section{INTRODUCTION}

Brimonidine tartrate is a relatively selective alpha-2 adrenergic agonist for ophthalmic use. The chemical name of brimonidine tartrate is 5-bromo-6-(2-imidazolidinylideneamino) quinoxaline L-tartrate. It has a molecular weight of 442.24 as the tartrate salt, and is soluble in water $(5.6 \mathrm{mg} / \mathrm{ml})$ at $\mathrm{pH} 6.5[1]$.

Brimonidine is indicated for the lowering of intraocular pressure in patients with open-angle glaucoma or ocular hypertension. It has a peak ocular hypotensive effect occurring at two hours post-dosing [1]. Fluorophotometric studies in animals and humans suggest that brimonidine tartrate has a dual mechanism of action by reducing aqueous humor production and increasing uveoscleral outflow. A meta-analysis of randomized clinical trials performed by van der Valk et al. (2005) demonstrates that brimonidine is comparable to other agents like beta-blockers, prostaglandin analogs and carbonic anhydrase inhibitors regarding its IOP-lowering effect [2].

In humans, systemic metabolism of brimonidine is extensive. It is metabolized primarily by the liver. Urinary excretion is the major route of elimination of the drug and its metabolites and approximately $87 \%$ of an orally-administered radioactive dose was eliminated within 120 hours, with $74 \%$ found in the urine [1].

\section{AIM}

The purpose of the present study was to evaluate the pharmacodynamic equivalence of two brimonidine tartarate $0,2 \%$ ophthalmic preparations in healthy volunteers.

\section{METHODS}

This paper is part of commercial phase- 1 clinical trial, sponsored by Hexal AG, Holzkirchen, Germany, who gave the permission for publication.

\section{Study design}

The test drug (Brimonidine Tartrate Ophthalmic Solution $0.2 \%$ ) was manufactured by Sandoz Canada Inc. Alphagan ${ }^{\circledR}$ ophthalmic solution $0.2 \%$ manufactured by Allergan Ltd., United Kingdom was used as a reference product.

The study was performed in accordance with the ethical standards as laid down in the 1964 Declaration of Helsinki and its later amendments, and in accordance with regulation documents [3-7]. The study was reviewed and approved by the ethics committee of the University Hospital "Tsaritsa Joanna-ISUL", Bulgaria and by the Bulgarian Drug Agency.

The study was performed at the Clinic of Clinical Pharmacology and Therapeutics and the Clinic of Ophthalmology, University Hospital "Tsaritsa Joanna-ISUL", Medical University of Sofia, Bulgaria.

The most important inclusion criteria were as follows: age between 18 and 55 years, physically and mentally healthy, IOP between 16 and $21 \mathrm{mmHg}$ (mean value of 3 measurements) at screening, and normal body weight (BMI between 19 and $27 \mathrm{~kg} / \mathrm{m} 2$ ).

All participants gave their informed consent to participate in writing prior to inclusion in the study and after a complete written and verbal explanation of the nature, scope and possible consequences. A total number of 45 volunteers gave their informed consent for participation in the study and underwent the screening examination. Thirty six subjects met all inclusion and none of the exclusion criteria and were judged eligible for the study. Nine subjects did not meet one or more inclusion criteria or met one or more exclusion criteria. Thirty six volunteers were randomized in the study and all of them completed the study according to the protocol.

The results of all 36 study completers were subjected to statistical evaluation. 


\section{Procedures}

The clinical part of the study included a 12 hours overnight stay (on day 0) and further 6 hours confinement after dosing (on day 1) at the healthy volunteer unit of the clinical center for drug administration, measurement of intraocular pressure and assessment of local tolerability. Two visits were performed for entry and final examination (up to 7 days before and up to 7 days after dosing).

The volunteers spent the night before dosing at the healthy volunteer unit. In the morning on day 1 the volunteers received a standard breakfast between 7:00 and 7:30 a.m. The trial medication was administered between 9:15 and 10:50 a.m.: a single dose of 1 drop of the test product in the conjunctival sac of one eye and 1 drop of the reference drug in the conjunctival sac of the other eye. The administration of the study medication was performed always by the same investigator for all volunteers after completion of IOP measurement and was timely related to the pre-treatment measurement of IOP. The measurement of IOP was performed three times on each eye within 3 minutes, always by the same investigator and using the same tonometer for the same volunteer, always starting with the right eye, followed by the left eye. The mean value of the three measurements was taken for evaluation.

The resulting schedule was as follows:

- 0 min: administration of local anaesthetic eye drops into the first (right) eye

- 2 min: first measurement of IOP of the first (right) eye

- 3 min: second measurement of IOP of the first (right) eye

- 4 min: third measurement of IOP of the first (right) eye

- 5 min: administration of local anaesthetic eye drops into the second (left) eye

- 7 min: first measurement of IOP of the second (left) eye

- 8 min: second measurement of IOP of the second (left) eye

- 9 min: third measurement of IOP of the second (left) eye

- 15 min: administration of study medication ( 1 drop in the conjunctival sac) to the first (right) eye

- 20 min: administration of study medication (1 drop in the conjunctival sac) to the second (left) eye.
To reduce the possible systemic absorption, the lacrimal sac was compressed at the medial canthus (punctal occlusion) for one minute immediately following the instillation of each drop.

The sequence of administration was the same for all volunteers: the right eye was dosed first, followed by the left eye. The allocation of test and reference product to the left or to the right eye was randomized.

Another measurement of IOP of both eyes was performed two hours post dosing within a period of 9 minutes, following the same procedure as described above.

The measurement of IOP was performed by means of a Goldmann applanation tonometer. Immediately before each measurement of IOP fluorescein was applied using sterile, individually packed Fluorescein strips (Haag-Streit AG, Switzerland). The tonometer was calibrated according to the instructions of the manufacturer.

The present trial was performed under observer-blinded conditions. The investigator responsible for the measurement of IOP and the evaluation of local tolerability and vital signs measurement (always the same person for the same volunteer) was held blind regarding the identity of test and reference product. For achieving blindness the dosing was performed in a separate room by a separate investigator responsible only for drug dosing.

The local tolerability was assessed before dosing and $15 \mathrm{~min}, 1,2$ (before the IOP measurement), and 6 hours post dose in each eye by rating following symptoms: blurred vision, ocular burning, epiphora and hyperemia.

Eye motility examination was performed by means of saccades assessment (by asking the subject move his eye quickly to a target at the far right, left, top and bottom) and slow tracking assessment (using the so called 'follow my finger' test).

Pupillary function examination included inspecting the pupils for equal size (1 $\mathrm{mm}$ or less of difference may be normal), regular shape, reactivity to light, and direct and consensual accommodation.

Visual acuity measurement was performed using a Snellen chart. The standard definition of normal visual acuity $(20 / 20$ or $6 / 6$ vision) is the ability to resolve a spatial pattern separated by a visual angle of one minute of arc. 
The evaluation of the anterior eye was performed by means of a slit lamp biomicroscope (Reichert).

The evaluation of the fundus was performed by means of the biomicroscope using corresponding lenses.

All additional ophthalmologic examinations were performed at screening visit for check of exclusion criterion and at the final visit and evaluated by the investigator as "normal" or "abnormal".

\section{Statistical analysis}

A total number of thirty-six male and female Caucasians were planned for inclusion. The sample size was calculated in respect of the primary target parameter (absolute decrease in IOP 2 hours post dose) and an estimated equivalence margin of $1.5 \mathrm{mmHg}$.

The resulting sample size was $\mathrm{n}=32$. Taking into account possible drop outs, 4 volunteers more than the number needed according to statistical considerations were planned for enrolment. The total number of volunteers to be enrolled and treated was thus 36 .
Table 1. Demographic data of the volunteers

\begin{tabular}{|l|c|c|}
\hline \multicolumn{1}{|c|}{$(\mathrm{n}=36)$} & Mean \pm SD & Min - Max \\
\hline Age [years] & $35.8 \pm 8.2$ & $23-54$ \\
\hline Height $[\mathrm{cm}]$ & $170.9 \pm 8.9$ & $155-188$ \\
\hline Weight $[\mathrm{kg}]$ & $67.9 \pm 12.5$ & $48-93$ \\
\hline BMI $[\mathrm{kg} / \mathrm{m} 2]$ & $23.1 \pm 2.8$ & $19-27$ \\
\hline female : male & \multicolumn{2}{|c|}{$19: 17$} \\
\hline
\end{tabular}

Figure 1. Comparative box 9 plot of absolute IOP decrease 2 hours post dose

Absolute decrease in IOP $(\mathrm{mmHg})$

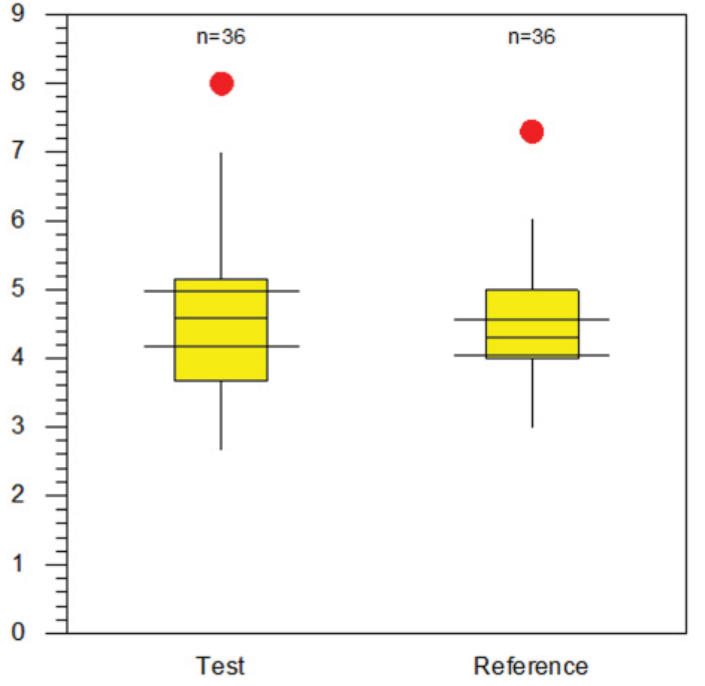

The pharmacodynamic equivalence of both products was evaluated by calculating the two-sided $95 \%$ confidence interval for the difference (test-reference) of the primary target parameter absolute decrease in IOP 2 hours post dose. The confidence intervals were determined by means of analysis of variance (ANOVA). The ANOVA model included treatment, administration pattern (which product was administered in which eye), and subject within pattern as factors. The $95 \%$ confidence interval was then compared with the predefined clinical acceptance range of \pm 1.5 mmHg.

The relative (as percentage of baseline) decrease in IOP 2 hours post dose of both products was evaluated as a secondary target parameter in the present study.

The safety parameters in this trial included the evaluation of local tolerability and vital signs (heart rate, blood pressure), clinical and laboratory examinations (carried out in a certified local clinical laboratory) at the beginning and at the end of the trial as well as the registration of adverse events and/or adverse drug reactions during the total duration of the trial.

\section{RESULTS}

All 36 volunteers who were randomized completed the study according to protocol. The demographic data of the volunteers are presented in Table 1. The results of the individual IOP measurements on day 1 (pre- dose and $2 \mathrm{~h}$ post dose) are presented in Table 2. The primary and secondary target parameters are summarized in Table 3.

The mean value of the primary target parameter "absolute decrease in intraocular pressure 2 hours post dose" was $4.60 \pm 1.26$ $\mathrm{mmHg}$ for the test formulation and $4.40 \pm 0.89$ $\mathrm{mmHg}$ for the reference formulation (Figure 1). The mean value of the secondary target parameter "relative decrease in intraocular pressure 2 hours post dose" was $27.89 \% \pm 7.48 \%$ for the test formulation and $26.70 \% \pm 5.25 \%$ for the reference formulation (Figure 2). The twosided $95 \%$ confidence interval calculated for the difference (test-reference) of the absolute decrease in intraocular pressure 2 hours post dose was between -0.275 and $0.670 \mathrm{mmHg}$ and thus entirely within the pre-defined acceptance range of $\pm 1.5 \mathrm{mmHg}$ (Table 4 ).

The local tolerability of both prepara- 


\begin{tabular}{|c|c|c|c|c|c|}
\hline \multirow{2}{*}{$\begin{array}{l}\text { Vol. Random } \\
\text { No. }\end{array}$} & \multirow{2}{*}{$\begin{array}{l}\text { Administration } \\
\text { pattern }\end{array}$} & \multicolumn{2}{|c|}{ IOP before dosing [mmHg] } & \multicolumn{2}{|c|}{ IOP $2 \mathrm{~h}$ post dosing [mmHg] } \\
\hline & & $\begin{array}{l}\text { MEAN Right } \\
\text { Eye [mmHg] }\end{array}$ & $\begin{array}{c}\text { MEAN Left } \\
\text { Eye [mmHg] }\end{array}$ & $\begin{array}{l}\text { MEAN Right } \\
\text { Eye [mmHg] }\end{array}$ & $\begin{array}{l}\text { MEAN Left } \\
\text { Eye [mmHg] }\end{array}$ \\
\hline 1 & OS-R/OD-T & 17.0 & 16.3 & 11.7 & 9.0 \\
\hline 2 & OS-R/OD-T & 16.0 & 16.0 & 11.5 & 12.0 \\
\hline 3 & OS-T/OD-R & 17.3 & 17.0 & 13.0 & 13.3 \\
\hline 4 & OS-T/OD-R & 16.0 & 16.0 & 12.0 & 12.0 \\
\hline 5 & OS-R/OD-T & 17.0 & 16.0 & 11.0 & 12.0 \\
\hline 6 & OS-R/OD-T & 17.3 & 17.7 & 13.0 & 13.0 \\
\hline 7 & OS-T/OD-R & 16.3 & 17.0 & 13.0 & 12.0 \\
\hline 8 & OS-T/OD-R & 16.0 & 16.0 & 13.0 & 13.3 \\
\hline 9 & OS-T/OD-R & 16.0 & 16.0 & 10.7 & 9.7 \\
\hline 10 & OS-R/OD-T & 16.0 & 16.7 & 13.0 & 13.0 \\
\hline 11 & OS-T/OD-R & 16.7 & 16.0 & 12.0 & 12.0 \\
\hline 12 & OS-R/OD-T & 16.0 & 16.7 & 13.0 & 12.7 \\
\hline 13 & OS-T/OD-R & 17.0 & 17.0 & 12.0 & 12.0 \\
\hline 14 & OS-R/OD-T & 16.7 & 16.0 & 10.3 & 11.3 \\
\hline 15 & OS-T/OD-R & 18.0 & 17.0 & 13.0 & 12.3 \\
\hline 16 & OS-R/OD-T & 16.0 & 16.0 & 11.0 & 11.7 \\
\hline 17 & OS-T/OD-R & 16.0 & 16.0 & 12.0 & 12.3 \\
\hline 18 & OS-T/OD-R & 16.0 & 16.0 & 13.0 & 8.0 \\
\hline 19 & OS-R/OD-T & 17.0 & 16.3 & 10.0 & 12.0 \\
\hline 20 & OS-R/OD-T & 16.7 & 16.7 & 13.7 & 13.0 \\
\hline 21 & OS-T/OD-R & 16.0 & 16.0 & 12.0 & 12.0 \\
\hline 22 & OS-R/OD-T & 17.3 & 17.0 & 12.3 & 12.0 \\
\hline 23 & OS-T/OD-R & 16.0 & 16.0 & 13.0 & 10.7 \\
\hline 24 & OS-R/OD-T & 17.3 & 17.0 & 13.0 & 12.0 \\
\hline 25 & OS-T/OD-R & 17.0 & 17.0 & 13.0 & 12.0 \\
\hline 26 & OS-R/OD-T & 16.3 & 17.0 & 13.0 & 12.7 \\
\hline 27 & OS-R/OD-T & 16.0 & 16.0 & 11.0 & 11.0 \\
\hline 28 & OS-T/OD-R & 16.0 & 16.0 & 13.0 & 13.0 \\
\hline 29 & OS-R/OD-T & 17.0 & 16.7 & 11.7 & 10.7 \\
\hline 30 & OS-R/OD-T & 16.7 & 17.0 & 12.0 & 11.7 \\
\hline 31 & OS-T/OD-R & 16.0 & 16.0 & 12.0 & 12.0 \\
\hline 32 & OS-T/OD-R & 16.0 & 16.0 & 11.7 & 12.7 \\
\hline 33 & OS-T/OD-R & 16.3 & 16.0 & 11.7 & 12.3 \\
\hline 34 & OS-R/OD-T & 16.0 & 16.0 & 12.7 & 10.7 \\
\hline 35 & OS-R/OD-T & 16.0 & 16.0 & 11.0 & 12.0 \\
\hline 36 & OS-T/OD-R & 17.0 & 17.0 & 12.0 & 10.3 \\
\hline
\end{tabular}

Table 2. Results of the individual IOP measurements on day 1 (pre-dose and 2 hours post dose)

OS - left eye

$O D$ - right eye

$\mathbf{R}$ - reference product

$\mathbf{T}$ - test product tions was good and revealed no clinically significant differences between both products. A total number of 8 non serious adverse events (AEs) were registered in 6 volunteers in the course of the trial: blurred vision, ocular burning, epiphora and ocular hypeaemia. Two AEs were observed in the eye treated with the test drug; 5 AEs were observed in the eye treated with the reference drug and 1 event was ob- served before administration of trial medication (baseline event). All 8 non serious AE's were followed by a complete restitution.

\section{DISCUSSION}

The market share of generic drugs has grown substantially in recent years. For example since the passage of the Waxman-Hatch Act in the 
Table 3. Primary and secondary target parameters: absolute and relative decrease in IOP 2 hours post dose of brimonidine tartarate $2 \mathrm{mg} / \mathrm{ml}$ eye drops test formulation and reference formulation, after an single dose of 1 drop in the right or left eye (arithmetic mean $\pm S D$, $n=36$ )

\begin{tabular}{|c|c|c|c|}
\hline & \multirow{2}{*}{\multicolumn{3}{|c|}{ Absolute Decrease in IOP (mmHg), primary endpoint }} \\
\hline & & & \\
\hline & Mean & SD & CV \% \\
\hline TEST & 4.60 & 1.26 & 27.38 \\
\hline \multirow[t]{3}{*}{ REFERENCE } & 4.40 & 0.89 & 20.20 \\
\hline & \multicolumn{3}{|c|}{ Relative Decrease in IOP (\% from baseline), secondary endpoint } \\
\hline & Mean & SD & CV $\%$ \\
\hline TEST & 27.89 & 7.48 & 26.81 \\
\hline REFERENCE & 26.70 & 5.25 & 19.68 \\
\hline
\end{tabular}

Figure 2. Comparative box plot of relative IOP decrease 2 hours 50 post dose

Relative decrease in IOP (\% from baseline)

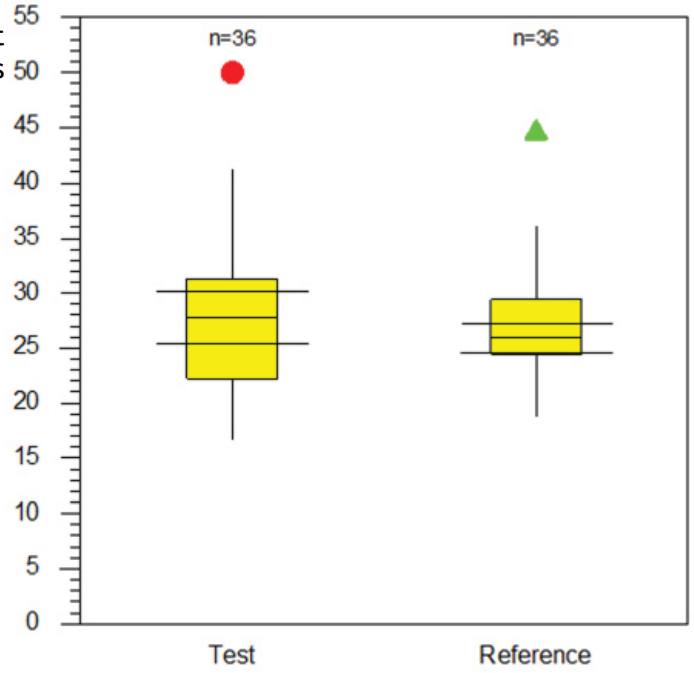

Table 4. 95\% confidence interval for the difference of the primary target parameter absolute decrease in IOP 2 hours post dose $(n=36)$

\section{Parametere pointestimator \\ $95 \%$ confidencelimits \\ difference \\ between means of absolute 0.197 $-0.275-0.670$ decrease of IOP}

USA the market share of generic products increased from $19 \%$ in 1984 to $50 \%$ in 2001. Pharmacokinetic bioequivalence trials are normally performed for the registration of generic products. Pharmacodynamic parameters can be used for demonstrating bioequivalence of locally applied, locally acting products as in such cases pharmacokinetic bioequivalence is not a suitable approach since plasma drug levels are not relevant for local efficacy [3]. This refers to products locally applied to the eye for the treatment of glaucoma such as beta blocking agents, carboanhydrase inhibitors, etc.. When performing a pharmacodynamic bioequivalence trial several important aspects have to be taken into account. In most of the cases pharmacodynamics equivalence trials are performed in patients using a clinical endpoint. In rare cases trials in healthy volunteers might also be feasible provided that the drug tested in the trial fulfills the following requirements: a) it has a pronounced and measurable pharmacodynamics effect in healthy volunteers and b) this effect is representative for the clinical efficacy in patients. Irrespective whether a pharmacodynamic bioequivalence trial is performed in patients or in healthy volunteers the limits within which a generic product is still defined as being "equivalent" to the reference product have to be a) justified based on their clinical relevance and $\mathrm{b}$ ) prospectively defined in the study protocol.

It has been demonstrated that brimonidine significantly reduces intraocular pressure in healthy volunteers [8-9]. This makes an equivalence trial in healthy subjects possible.

The equivalence limit of $1.5 \mathrm{mmHg}$ was chosen as the largest medically justifiable deviation of the test formulation compared to the reference formulation based on a recommendation published in an article in the Ophthalmology Times [10]. The same equivalence limit was also used by other authors [11-12], when comparing the efficacy of different formulations of timolol for the lowering of intraocular pressure, as well as by the authors of the current publication in two other clinical trials [13-14], for evaluating the pharmacodynamics equivalence of products containing dorzolamide and the combination of dorzolamide plus timolol. A difference of $1.5 \mathrm{mmHg}$ can be therefore regarded as a generally accepted border of clinical significance in glaucoma research.

The most frequently used study design in bioequivalence trial is cross-over design in which the same volunteer receives both study drugs in two different periods separated by an appropriate wash-out period. Data from the literature show that in the case of eye drops 
administration of topical carbonic anhydrase inhibitor and beta- blockers in one of both eyes has practically no effect on the contralateral eye [11-12]. A feasible alternative to a cross-over design is thus dosing of both eyes simultaneously: one of both eyes receives the test drug and the other one the reference product. Such study design was used by the same working group when evaluating the pharmacodynamics equivalence of dorzolamide [14]. The chosen design of the study was considered to be adequate to determine the pharmacodynamic target parameters of the test and reference preparations. As the maximum IOP lowering effect of both products was expected about 2 hours post dose, the assessment was performed at that time, considering that the sensitivity of the comparison (i.e. the ability to show difference between both products) would be the highest.

Both products caused a pronounced and almost identical decrease of IOP: $4.60 \pm$ $1.26 \mathrm{mmHg}$ after the test drug and $4.40 \pm 0.89$ $\mathrm{mmHg}$ after the reference product. These findings are well comparable to literature data. It has been demonstrated that the topical administration of brimonidine reduces the intraocular pressure in healthy volunteers by roughly 3 to $5 \mathrm{mmHg}$ compared to pre-dose values [1618].

The two-sided $95 \%$ confidence interval was calculated of the difference (test-reference) of the absolute decrease in IOP 2 hours post dose and then compared with the predefined confidence limits of $\pm 1.5 \mathrm{mmHg}$. The calculated confidence interval was between -0.275 and $0.670 \mathrm{mmHg}$ and thus within the acceptance range. The $95 \%$ confidence intervals are based on the data of 36 study completers.

The assessment of local tolerability together with the recording of vital signs and adverse events revealed no difference between the test and the reference preparation with respect to their safety profile: both products were well tolerated and showed no signs of systemic reactions.

The findings regarding the pharmacodynamic parameter (lowering of IOP) are coherent and demonstrate the therapeutic equivalence of the test product (Brimonidine Tartrate Ophthalmic Solution 0.2\%) with the reference product (Alphagan ${ }^{\circ}$ ophthalmic solution $0.2 \%$ ). They can thus be considered as interchangeable for the treatment of patients with ocular hypertension.

\section{CONCLUSION}

Brimonidine Tartrate Ophthalmic Solution $0.2 \%$ was pharmacodynamically equivalent to the reference preparation $\left(\right.$ Alphagan $\left.^{\circ}\right)$ with respect both to efficacy and safety.

\section{LIMITATIONS OF THE STUDY}

The main limitation of the present study is the fact that it was performed in healthy volunteers with normal intraocular pressure.

\section{ACKNOWLEDGEMENT}

The authors would like to thank the volunteers and staff who participated in this study.The authors were fully responsible for the entire content and editorial decisions, and have approved the final version.

\section{AUTHOR DISCLOSURE STATEMENT}

The clinical study has been sponsored by Hexal AG, Holzkirchen, Germany. U ThyroffFriesinger is a employee of Hexal AG.Rossen Koytchev and Wolfram Richter are employees of CCDRD AG, the CRO which was authorised by Hexal AG to organise this clinical trial. Russka Hristova, Irena Demircheva, Andrey Petrov and Emil Gatchev received a remuneration by CCDRD AG for performing the clinical part of the study.

\section{REFERENCES}

\section{Prescribing information Alphagan $\circledast 2001$}

2. van der Valk R, Webers CA, Schouten JS, Zeegers $M P$, Hendrikse F, Prins MH. Intraocular pressure-lowering effects of all commonly used glaucoma drugs: a meta-analysis of randomized clinical trials. Ophthalmology. 2005 Jul;112(7):1177-1185?

3. CPMP Note for Guidance on the Clinical Requirements for Locally Applied, Locally Acting Products Containing Known Constituents (CPMP/EWP/239/95 final).

4. CPMP Note for Guidance on the Investigation of Bioavailability and Bioequivalence. CPMP/EWP/ QWP/1401/98. July 2001.

5. CPMP: Note for Guidance on Modified Release 
Oral and Transdermal Dosage Forms: section II (Pharmacokinetic and Clinical Evaluation) (CPMP/ EWP/280/96, Jan. 2000).

6. Directive 2001/83/EEC of the European parliament and of the Council of 6 November 2001 on the Community code relating to medicinal products for human use.

7. ICH Topic E 6. Guideline for Good Clinical Practice. Step 5, Consolidated Guideline from 01.05.1996. Note for Guidance on Good Clinical Practice (CPMP/ICH/135/95). Jan.1997.

8. Inan UU, Ermis SS, Orman A, Onrat E, Yucel A, Ozturk F, Asagidag A, Celik A. The comparative cardiovascular, pulmonary, ocular blood flow, and ocular hypotensive effects of topical travoprost, bimatoprost, brimonidine, and betaxolol.J Ocul PharmacolTher. 2004 Aug;20(4):293-310.

9. Jonescu-Cuypers CP, Harris A, Ishii Y, Kagemann L, Gazozi HJ, Rotenstreich Y, Chung HS, Martin B. Effect of brimonidine tartrate on ocular hemodynamics in healthy volunteers. J Ocul Pharmacol Ther. 2001 Jun;17(3):199-205.

10. Opthalmology Times. Dec. 15, 2001: Approach scientific literature with open mind, eye for detail.

11. Hofmann HM, Feicht B, Brunner-Ferber E, Lippa E, von Denffer H. [MK-507 (L-671 152): local tolerance and effectiveness of a new local carbonic anhydrase inhibitor in healthy probands. Fortschr Ophthalmol. 1991;88(5):513-514.

12. Rouland JF, Morel-Mandrino P, Elena PP, Polzer $\mathrm{H}$, Sunder Raj P. Timolol $0.1 \%$ gel (Nyogel $0.1 \%$ once daily versus conventional timolol $0.5 \%$ solution twice daily: a comparison of efficacy and safety. Ophthalmologica. 2002 Nov-Dec;216(6):449-454.

13. Gatchev E., Petrov A., Kolev E., Hristova R., Demircheva I., Koytchev R., Richter W., Tegel F., Thyroff-Friesinger U. Pharmacodynamic equivalence of two preparations of eye drops containing $20 \mathrm{mg}$ dorzolamide and $5 \mathrm{mg}$ timolol in healthy volunteers. Arzneimittelforschung (Drug research) 2011; 61 (5): 282-286.

14. Gatchev E., Petrov A., Hristova R., Demircheva I., Thyroff-Friesinger U., Richter W.KoytchevR. Pharmacodynamic equivalence study of two preparations of eye drops containing dorzolamide in healthy volunteers. Hospital Pharmacology. 2016; 3 (2): 379-386.

15. Pfeiffer N, Hennekes R, Lippa EA, Grehn F, Garus $\mathrm{H}$, Brunner-Ferber FL. A single dose of the topical carbonic anhydrase inhibitor MK-927 decreases IOP in patients. Br J Ophthalmol. $1990 \mathrm{Jul} ; 74(7)$ :405408.

16. Nordlund JR, Pasquale LR, Robin AL, Rudikoff MT, Ordman J, Chen KS, Walt J. The cardiovascular, pulmonary, and ocular hypotensive effects of $0.2 \%$ brimonidine. Arch Ophthalmol. 1995 Jan;113(1):7783.
17. Inan UU, Ermis SS, Orman A, Onrat E, Yucel A, Ozturk F, Asagidag A, Celik A. The comparative cardiovascular, pulmonary, ocular blood flow, and ocular hypotensive effects of topical travoprost, bimatoprost, brimonidine, and betaxolol. J Ocul Pharmacol Ther. 2004 Aug;20(4):293-310

18. Tsukamoto H, Larsson LI. Aqueous humor flow in normal human eyes treated with brimonidine and dorzolamide, alone and in combination. Arch Ophthalmol. 2004 Feb;122(2):190-193. 


\section{Farmakodinamički pristup za dokazivanje ekvivalencije dva oftalmološka rastvora koja sadrže brimonidin tartrat $0,2 \%$ kod zdravih dobrovoljaca}

Ruska Valcheva Hristova ${ }^{1}$, Irenna Stojanova Demircheva ${ }^{1}$, Andrey Dimitrov Petrov ${ }^{2}$, Emil M. Gatchev², Ursula Thyroff-Friesinger ${ }^{3}$, Wolfram Hagen Richter ${ }^{4}$, Rossen Krumov Koytchev ${ }^{4}$

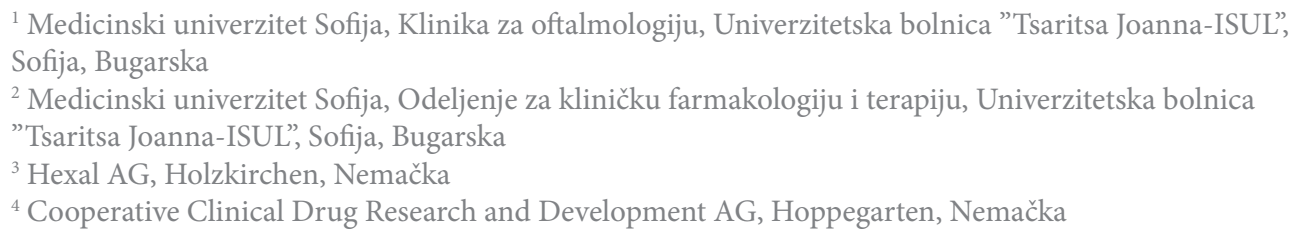

\section{KRATAK SADRŽAJ}

Uvod: Brimonidin tartarat oftalmološki rastvor (CAS registarski broj: 70359-46-5) je agonist alfa-2-adrenergičnih receptora, indikovan za smanjenje intraokularnog pritiska kod pacijenata sa otvorenim komornim uglom ili očnom hipertenzijom.

Cilj: Cilj ove komercijalne studije I faze, publikovane uz saglasnost sponzora, je da ispita farmakodinamsku ekvivalenciju dva leka oftalmološka rastvora koji sadrže Brimonidin tartarat $0,2 \%$ kod zdravih dobrovoljaca.

Metodologija: Studija je sprovedena kao unicentrična, randomizovana, single-dose, observer-slepa, single period studija, kod 36 zdravih dobrovoljaca. Svaki dobrovoljac je dobio sukcesivno na randomiziran način po jednu dozu: 1 kap test leka ili referentnog leka, u suzni kanal i levog i desnog oka. Intraokularni pritisak (IOP) oba oka meren je skrining metodom, pre davanja doze leka i 2 sata nakon davanja leka i na kraju ispitivanja pomoću Goldmann apanacionog tonomera. Kao primarni ciljani parametar farmakodinamske ekvivalencije definisan je absolutno smanjenje IOP nakon 2 sata od davanja doze leka. Izračunat je $95 \%$ interval pouzdanosti za testiranje razlike primarnih ciljnih parametara i komparisan sa pre-definisanim ekvivalentnim rasponom \pm $1.5 \mathrm{mmHg}$.

Rezultati: Posle primene testirane i referentne formulacije opservirano je smanjenje IOP za $4.60 \pm 1.26 \mathrm{mmHg}$ i $4.40 \pm 0.89 \mathrm{mmHg}$. Prosečna razlika iznosila je $+0.197 \mathrm{mmHg}$ sa $95 \%$ intervalom pouzdanosti od -0.275 do $0.670 \mathrm{mmHg}$ što je bilo u okviru prethodno definisanog raspona ekvivalencije. Oba proizvoda su imala veoma dobar profil bezbednosti i podnošljivosti.

Zaključak: Brimonidin tartarat oftalmološki rastvor $0.2 \%$ je farmakodinamski ekvivalentan sa referentnim lekom (Alphagan ${ }^{\circledR}$ ).

Ključne reči: farmakodinamska ekvivalenca, brimonidin, oftalmološki rastvor 